\title{
http://bjas.journals.ekb.eg
}

\section{Evaluation of Nano-Based-ELISA for Serodiagnosis of Human Toxoplasmosis}

A.S.Al hamshary ${ }^{1}$, I.R.Bayoumi ${ }^{2}$, N.S.Aly ${ }^{1}$, R.E.Omar ${ }^{1}$, D.A.Mohammed ${ }^{1}$, Y.M.Marei ${ }^{3}$ and G. A.Rashed ${ }^{1}$ ${ }^{1}$ Parasitology Dept., Faculty of Medicine, Benha Univ., Benha, Egypt

${ }^{2}$ ImmunoParasitology Dept., Theodor Bilharz Research institute, Imbaba, Giza, Egypt

${ }^{3}$ Biochemistry and Molecular Biology,Dept., Faculty of Medicine, Benha Univ., Benha, Egypt

E-Mail:dinahady87@gmail.com

\section{Abstract}

Toxoplasma surface antigen 1(SAG1) is a major surface antigen involved in the diagnosis of toxoplasmosis. Although it only accounts for 3-5\% of total T. gondii protein, the majority of the antibodies are reactive against SAG1 during infection. SAG1 has potent immunogenicity and immune-reactivity; therefore, it is widely applied in diagnostic techniques. Will assess the symptomatic execution of a novel nano symptomatic elisa test Previously, serodiagnosis for human toxoplasmosis. Generation for list 1 What's more its purification might have been carried accompanied Eventually Tom's perusing preparation about igigi polyclonal antibodies Also its purification, characterization Furthermore conjugation with gold nanoparticles identification of Toxoplasma (SAG1) in the serum by nano-gold sandwich elisa uncovered $89.2 \%$ affectability Also 94\%, specificity. Nano-gold elisa method is a delicate test to identification of mankind's toxoplasmosis.

\section{Introduction}

Toxoplasmosis may be An ailment initiated Toward intracellular protozoan parasite apicomplexan from claiming overall appropriation named Toxoplasma gondii1. More or less $30 \%$ of the reality populace endure starting with $t$. Gondii infection2. In spite of the fact that those toxoplasmosis spoiling may be asymptomatic Around immunocompetent individuals, it might prompt not kidding obsessive impacts to both immunodeficient patients What's more intrinsic cases [3].

Toxoplasmosis may be Additionally a critical reason for chorioretinitis, particularly over people with an impeded safe framework. On these conditions, a fast Furthermore exact analysis is required to empower start for anti-parasitic medication as punctual Likewise workable will enhance those prognosis [4].

The the vast majority dependable symptomatic strategy to toxoplasmosis is identifying the pathogen, Yet this may be costly, chance expending Furthermore lesquerella touchy. The elisa identifying Toxoplasma-specific antibodies might have been found on be very delicate (92\%) What's more particular (91\%) which might have been utilized as a reference test5. T. Gondii produces dissolvable antigens that need aid discharged under group tissues and the blood stream6. Those identification about CAg may a chance to be of service for following the ailment. It might a chance to be that's only the tip of the iceberg dependable over immunizer identification On account it straightforwardly reflects those viability Furthermore amount about parasites in the group. Those identification about CAg might be supportive in the finding about toxoplasmosis, particularly

over immunocompromised patients whose serological reaction could be impaired [7].

SAGI may be stage specific, distinguished just in the tachyzoite stage, What's more absent in the bradyzoite stage 8 . This antigen will be abundant on the surface of both extracellular What's more intracellular tachyzoites 9 . It need likewise been news person that SAG1 could inspire a disappointment incendiary procedure to An mouse model from claiming pathogen-driven ileitis[10]. However, those living part of this surface protein stays vague. SAG1 is recognized Likewise a paramount nomination antigen over symptomatic tests, with no referred to cross-reactivity for proteins starting with different microorganisms [9].

Nanodiagnostics include the utilization from claiming nanotechnology over clinical finding should meet the requests for expanded affectability and early identification in lesquerella occasion when. Nanomaterials bring an expansive surface zone that empowers connection for vast number of focus particular atoms about premium to ultra-sensitive identification. Traditional techniques would restricted to accomplish this ultra-sensitivity. Nanotechnology empowers identification of a couple microorganisms or target atomic analytes particular to pathogens. Also, it Might permit fast What's more ongoing identification of the pathogens with generally little test volumes[11].

\section{Material and method}

This study was conducted in the Medical Parasitology Department, Faculty of Medicine, Benha University, Benha, during the period from January 2017 to January 2020 after approval of the research ethical committee Benha Faculty of Medicine.

\section{Participants}

Pregnant females going to ante-natal forethought done outpatients facility from claiming Gynaecology What's more obstetrics division for Benha school Hospital, Benha showing clinic Also ain Shams college (Al-Damerdash) healing center. Those destination of the examine might have been demonstrated will every last bit pregnant females take part in this fill in Also educated assent might have been taken from every one.

This examine might have been directed looking into 87 people. Grouping of the participates were done Concerning illustration follow: gathering I: $37 \mathrm{t}$. 
Gondii contaminated patients (detected Toward certain iga g What's more /or IgM). Aggregation II: 30 patients harboring different parasites over $t$. Gondii: 10 patients contaminated with c. Parvum, 10 patients contaminated with g. Lamblia Furthermore 10 patients contaminated with e. Histolytica. GroupIII: 20 Obviously solid people nothing from toxoplasmosis What's more other parasitic infections served Likewise non contaminated control.

Sera were divided Also put away In $-70^{\circ} \mathrm{C}$ until required.

\section{Preparation of SAG I of T. gondii}

In the present work $\mathrm{T}$. gondii antigens were prepared from peritoneal exudates of BALB/c mice infected 3 days earlier with tachyzoites of $\mathrm{T}$. gondii RH strain, as previously described [12].

T. gondii RH strain tachyzoites were used for prepatation of SAG1. Purification of SAGI was done by DEAE-Sephadex A-50 ion exchange chromatography [13].

The antigenicity of the purified Toxoplasma antigen was tested by indirect ELISA technique [14].

\section{Prodution of IgG pAbs against SAG1 antigen Animals}

Two New Zealand white male rabbits, $\begin{array}{lll}\text { weighting approximately } & 1.5 \mathrm{Kg} \text { and about }\end{array}$ two months age, purchased from rabbit research unit (RRU), Agriculture Faculty, Cairo University. The rabbits were housed for four weeks (experiment duration) in the animal house in Theodore Bilharz Research Institute (TBRI) under standard laboratory care at $21^{\circ} \mathrm{C}, 16 \%$ moisture, filtered drinking water with additional salts $1 \mathrm{~cm} / 5$ liter and vitamin $1 \mathrm{~cm} / 10$ liter. Diet contain $15 \%$ protein, $3 \%$ fat and $22 \%$ fiber purchased from RRU.

\section{Immunization of the rabbit for production of polyclonal antibodies}

Hang i might have been utilized for inoculation about rabbits to generation from claiming antiToxoplasma polyclonal antibodies. SAG1 antigen blended with a equivalent volume for complete Freund's adjuvant (CFA; Sigma, St. Louis, MO, USA). Three sponsor doses were given, each holding $0.5 \mathrm{mg}$ antigen emulsified clinched alongside an equivalent volume for inadequate. Freund's adjuvant (IFA, Sigma); those primary boosting might have been provided for 2 weeks then afterward those priming dose, and the Emulating boosting doses were provided for at weekly intervals, as past described[15].

Purification from claiming anti-Toxoplasma polyclonal antibodies anti-Toxoplasma immunizer might have been completed utilizing distinctive purification steps including half ammonitic sulfide precipitation16. Those technique accompanied Toward $7 \%$ caprylic corrosive precipitation technique [17].
Those sub-atomic weight might have been controlled Toward SDS-PAGE, Likewise formerly portrayed 18. Reactivity for rabbit anti- Toxoplasma igigi polyclonal antibodies against A large number parasitic antigens Toward backhanded elisa [19].

\section{Gold Nanoparticles}

Gold nanoparticles were purchased from Nano tech Egypt Company (6 October City, Cairo, Egypt).

Standardization of nano sandwich ELISA used for detection of Toxoplasma antigen was done. In nano sandwich ELISA, anti-Toxoplasma IgG pAb conjugated with gold Nano particles used as antigen capture (coating $\mathrm{Ab}$ ) and anti- Toxoplasma IgG pAb conjugated with HRP as detecting antibody.

\section{Detection of SAG1 in the sera by nano-gold sandwich ELISA \\ Principle}

A novel nano-gold sandwich ELISA using conjugated anti-Toxoplasma pAb with gold nanoparticles as the capture antibodies and antiToxoplasma $\mathrm{pAb}$ conjugated with $\mathrm{HRP}$ as the conjugated antibodies. The use of Nano beads in the immunoassay provide high binding capacity as a solid phase and rapid reaction kinetics of solutions with the simple separation of bound and unbound materials on the solid phase. They may provide the chance of enhancing the antigen detection in the immunoassay [20].

\section{Procedure}

Polystyrene microtiter plates were covered with $100 \mathrm{ml} /$ well of purified igigi pAb conjugated for Nano-gold molecule as a catch immunizer weakened On $8 \mathrm{ml}$ carbonate buffer, ph 9. 6. Those plates were washed 3 times with An washing cushion $(0.1 \mathrm{~m}$ PBS/Tween, ph 7. 4/Tween). Those spare locales were blocked for $200 \mathrm{ml} /$ well about $0.1 \mathrm{zBSA} / 0.1 \mathrm{~m}$ PBS/T, ph 7.4 and incubated for $1 \mathrm{~h}$ at $379 \mathrm{C}$. Those plates were washed 5 times for $0.1 \mathrm{~m} \mathrm{PBS} / \mathrm{T}$. Sera $(100 \mathrm{ml} /$ well $)$ were included Furthermore incubated to $2 \mathrm{~h}$ In $379 \mathrm{C}$, and the plates were washed 3 times. Peroxidase-conjugate igigi pAbs $(100 \mathrm{ml} / \mathrm{well})$ weakened done pbs were dispensed, Also plates were incubated to $2 \mathrm{~h}$ In 379C. The response might have been imagined by s were as about $100 \mathrm{ml} /$ well about O-phenylene diamine substrate result for $30 \mathrm{~min}$ in the dim toward room temperature. The response might have been quit Eventually Tom's perusing including $50 \mathrm{ml} /$ well for $8 \mathrm{n} \mathrm{H} 2 \mathrm{SO} 4$, and the plates were peruse toward $492 \mathrm{~nm}$ for a elisa microplate onlooker (Bio Rad).

\subsection{Statistical analysis}

Data are expressed as mean \pm standard deviation (SD) or percentages $(\%)$.

\section{Results}

Detection of Toxoplasma antigen (SAG1) in the serum samples by nano-gold sandwich ELISA. 
Toxoplasma surface antigen grade I (SAG1) level was measured at OD reading at $492 \mathrm{~nm}$. It was necessary at first to determine the cut off point for positivity or the line of demarcation between positive and negative data.

Cut off values =mean $O D$ reading of negative controls +2SD of negative result.

The tested samples showing OD reading $>$ cut off values were considered positive for Toxoplasma gondii. The cut off value was 0.467 When detecting Toxoplasma (SAG1) in the serum, the results were positive in 33 cases of group 1, while 4 cases were negative. In group II (patient with other parasites) only 3 cases were detected as positive ( 2 cases with Giardia lambelia and and 1with Entamoeba histolytica), while other 27 cases were negative. All healthy control cases were negative. The sensitivity was $89.2 \%$. and the specificity was found to be $94 \%$.

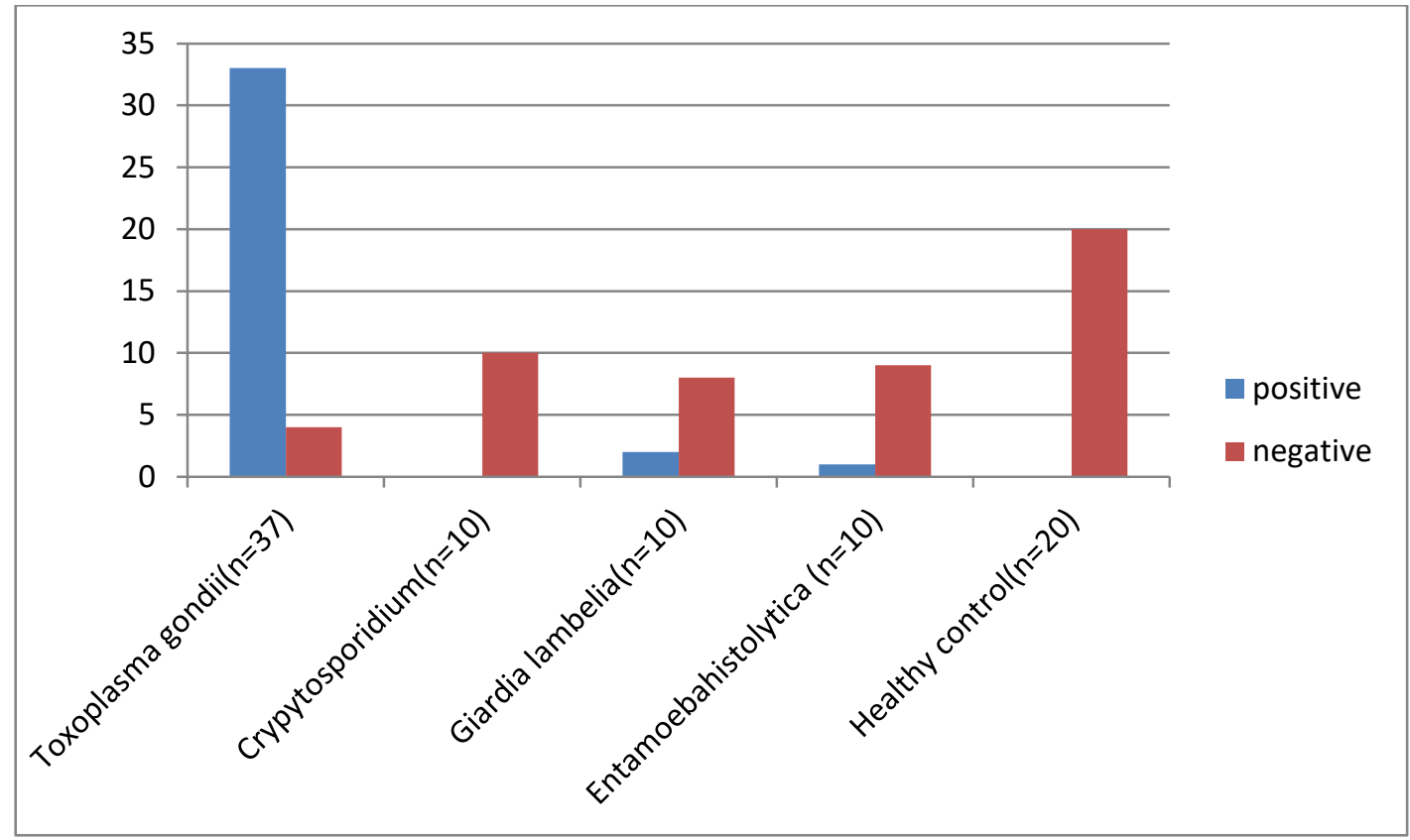

Fig (1) Results of Toxoplasma surface antigen grade I detection in the serum samples using nano sandwich ELISA in the different studied groups.

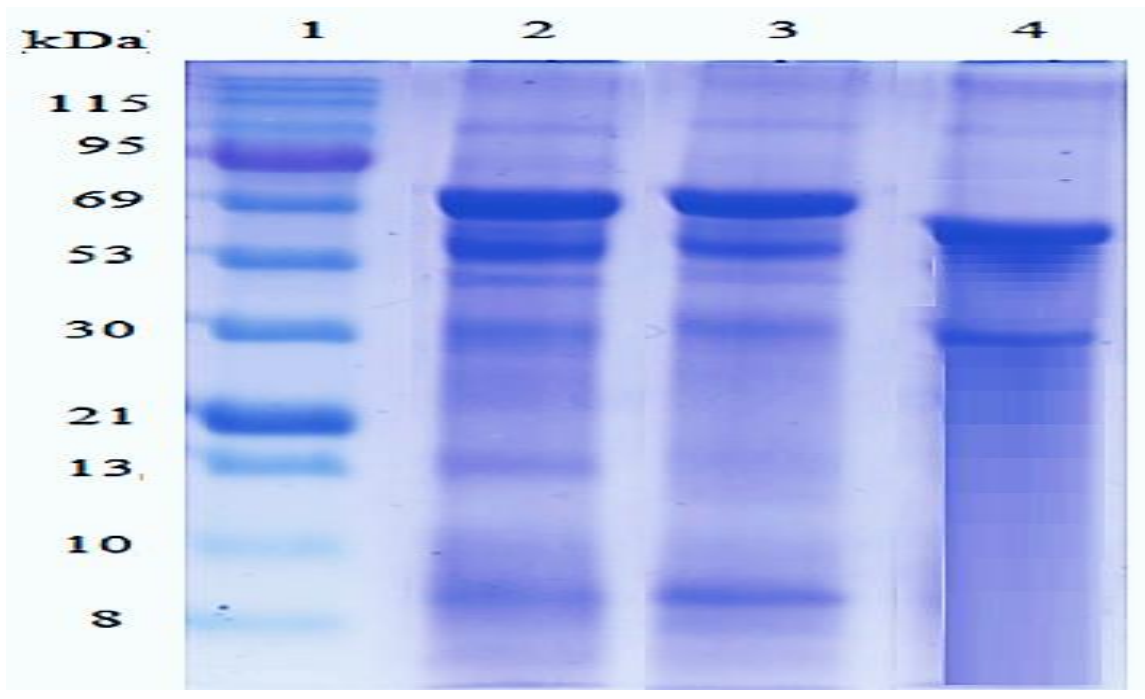

Fig (2) $12.5 \%$ SDS-PAGE of anti - Toxoplasma IgG polyclonal antibodies before and after purification (stained with coomassie blue).

Lane 1 Molecular weight of standard protein. Lane 2 Crude anti-T. godii IgG-pAb (before purification). Lane 3 Precipitated proteins after 50\% ammonium sulfate treatment. Lane 4 Purified IgG-pAb after $7 \%$ caprylic acid treatment 
Table (1) Reactivity of rabbit anti- Toxoplasma IgG polyclonal antibodies against many parasitic antigens by indirect ELISA.

\begin{tabular}{lc}
\hline Parasitic antigen & OD readings at $\mathbf{4 9 2} \mathbf{~ n m}(\mathbf{M} \pm \mathbf{S D})$ \\
\hline Toxoplasma gondii & $1.82 \square 0.247$ \\
Cryptosporidium & $0.278 \square 0.073$ \\
E. histolytica & $0.197 \square 0.012$ \\
G. lambilia & $0.219 \square 0.07$ \\
\hline
\end{tabular}

$\mathrm{OD}=$ optical density; $\mathrm{SD}=$ standard deviation and $\mathrm{M}=$ mean.

Table (2) Determination of the optimum concentration of purified anti- Toxoplasma IgG polyclonal antibody as a coating layer in nano sandwich ELISA.

\begin{tabular}{|c|c|c|c|c|c|}
\hline Coating dilution & $5 \mu \mathrm{g} / \mathrm{ml}$ & $10 \mu \mathrm{g} / \mathrm{ml}$ & $15 \mu \mathrm{g} / \mathrm{ml}$ & $20 \mu \mathrm{g} / \mathrm{ml}$ & $25 \mu \mathrm{g} / \mathrm{ml}$ \\
\hline $\begin{array}{l}\text { OD Value } \\
\text { At } 492 \text { nm }\end{array}$ & 1.6 & 1.9 & 1.7 & 1.4 & 1.4 \\
\hline
\end{tabular}

Table (3) Determination of the optimum concentration of conjugate antibody in nano sandwich ELISA.

\begin{tabular}{lccccc}
\hline Coating dilution & $\mathbf{5} \boldsymbol{\mu g} / \mathbf{m l}$ & $\mathbf{1 0} \boldsymbol{\mu g} / \mathbf{m l}$ & $\mathbf{1 5} \boldsymbol{\mu g} / \mathbf{m l}$ & $\mathbf{2 0} \boldsymbol{\mu g} / \mathbf{m l}$ & $\mathbf{2 5} \boldsymbol{\mu g} / \mathbf{m l}$ \\
\hline $\begin{array}{l}\text { OD Value } \\
\text { At } \mathbf{4 9 2} \mathbf{~ n m ~}\end{array}$ & 1.6 & 1.5 & 1.7 & 1.4 & 1.4 \\
\hline
\end{tabular}

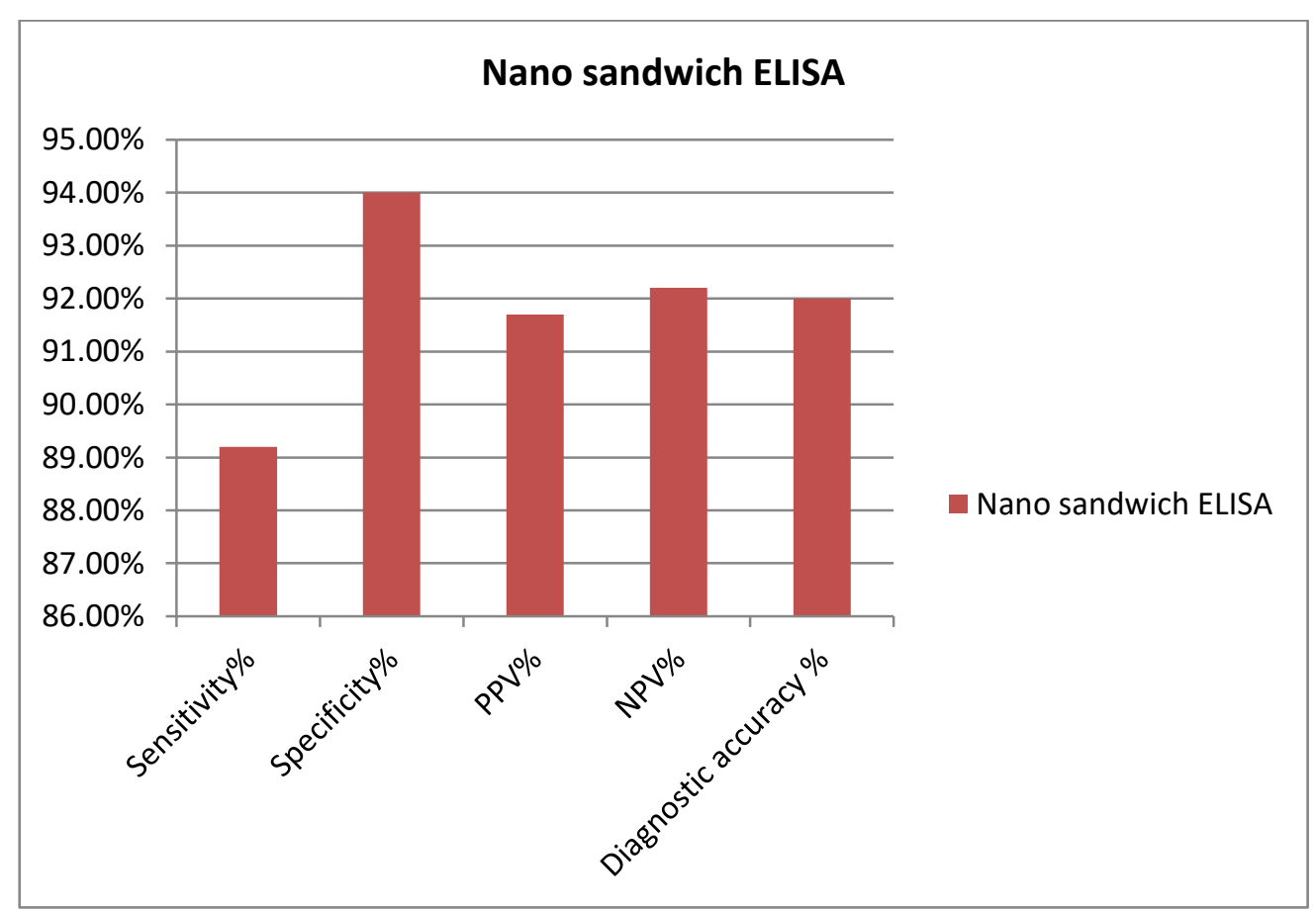

Fig (3) Sensitivity; Specificity; PPV; NPP and diagnostic accuracy percentage of nano sandwich ELISA.

\section{Discussion}

Those finding from claiming toxoplasmosis may be mossycup oak ordinarily aggravated Eventually Tom's perusing serological implies with identification about particular antibodies [21]. Despite serological testing need been a standout amongst those significant symptomatic for toxoplasmosis, it need huge numbers limitations; it might come up short with recognize particular anti-
Toxoplasma ignace jan paderewski or igigi Throughout the animated stage for infection, in light these antibodies might not be prepared until following a few weeks about parasitemia. Furthermore, the test might fizzle with identify $t$. Gondii spoiling for specific immunocompromised patients because of the reality that the titers for particular anti-Toxoplasma antibodies might neglect on Ascent in this kind of tolerant [22]. 
Indeed, identification about t. Gondii antigen minimizes the issues faced when utilizing serodiagnostic assays Also facilitates finding in troublesome situations.

Our objective in this consider is on assess the symptomatic execution of a novel nano -diagnostic sandwich elisa test (Nano-gold globules built ELISA) clinched alongside serodiagnosis of mankind's toxoplasmosis Exploring an viable early finding could make An enter step towards aversion from claiming this sickness What's more its difficulties. In view of identification of Toxoplasma surface antigen review i (SAG I), Also preparation from claiming its particular polyclonal antibodies Furthermore purification were basic.

Nanotechnology empowers identification of a couple of microorganisms or target atomic analytes particular with pathogens. Also, it Might permit fast Furthermore ongoing identification of the pathogens with generally little example volumes [23].

Gold nanoparticles (AuNPs) have exceptionally helter skelter absorption coefficients, permitting higher affectability to optical identification strategies over routine dyes. Those solid absorption about AuNPs need been utilized within colorimetric identification of analytes, by prompting amassed from claiming AuNPs in the vicinity about particular analytes [24].

Identification for Toxoplasma (SAG1) in the serum Eventually Tom's perusing nano-gold sandwich elisa uncovered that 33out from claiming 37 instances (89. 2\%) about t. Gondii contaminated patients (group I) were certain Also 4 cases (10.8\%) offered false negative comes about. On bunch ii (patient with other parasites) 3 out of 30 cases (10\%) offered false sure comes about. No cross response (false certain results) distinguished clinched alongside aggregation iii (healthy control ). So, Sensitivity, Specificity, PPV, NPP What's more symptomatic correctness rate of nano-gold sandwich elisa in the serum tests might have been $89.2 \%, 94 \%$, $91.7 \%, 92.2 \%$ and $92 \%$ individually.

The outcomes showed that nanodiagnostic test altogether increment those sensitivity, PPV Furthermore symptomatic exactness compared with sandwich elisa. This implies that the utilization for gold nanoparticles offer the possibility preference from claiming moving forward those affectability of the symptomatic tests to toxoplasmosis.

[18] demonstrated higher affectability (98\%) Furthermore specificity (96. 4\%) from claiming attractive nanoparticles (IMB-ELISA) over universal elisa (sensitivity 92\% What's more specificity 92. $7 \%$ ) clinched alongside analysis from claiming toxoplasmosis [25].

[22] utilized photoluminescent nanomaterials, those quantum dot, produced microarrays for identification about antibodies against antigens TORCH, getting a affectability What's more specificity more stupendous over $85 \%$, for rates comparable of the gold standard test, elisa. However, this microarray may be recommended as a test to make utilized within screening, Likewise it will be quick (about $20 \mathrm{~min}$ ) What's more obliges ten times lesquerella antigen The point when contrasted with elisa [26].

Gold NPs when conjugated for anti-HSP70 monoclonal antibodies demonstrated should be extremely delicate in the identification from claiming intestinal sickness antigen [27]. Polystyrene NPs conjugated for polyclonal igigi antibodies particular with p. Falciparum indicated $100 \%$ delicate brings about finding from claiming intestinal sickness [28].

[3] indicated helter skelter affectability comes about without cross response with different protozoa (E. Dispar, g. Lamblia and Blastocystis spp. ) when fluorescent silica NPs were conjugated for monoclonal anti-E. Histolytica clinched alongside analysis from claiming amebiasis [29].

[9]found that the affectability of identification about Giardia lamblia coproantigen in stool specimens utilizing Nano attractive globules speck elisa might have been higher (96. 9\%) versus dotELISA $(81.3 \%)$ [11].

To serodiagnosis about hydatidosis, [9] found that those affectability of nano-gold dot-ELISA might have been expanded should 95. 7\% versus dotELISA 88. 9\% [30].

Conjugation of the anti-protoscolex $\mathrm{pAb}$ for gold nano-particles expanded those affectability about nano-gold dot-ELISA should 95 . 7\% versus dotELISA 88. 9\% [30].

[12] assessed nano gold sandwich elisa (AuNPs) conjugated for anti-schistosomal monoclonal immune response (MAb) to its affectability Furthermore specificity over analysis for mankind's Schistosomasis mansoni. Those affectability Also specificity for elisa utilizing AuNPs -MAb to identifying circle schistosomal antigen (CSA) were $100 \%$ \& $97.8 \%$ [31].

Those prevalence from claiming nano based elisa In customary elisa over finding of parasitic illnesses might be clarified Toward the capacity Nano based with connect with matter toward the nanoscale, the improvement for nanotechnology materials Might conceivably augment sub-cellular What's more subatomic identification past the breaking points for routine symptomatic modalities[32].

Those little size Furthermore state of those nanobeads empower them should make uniformly disseminated inside the sample, consequently enhancing those viability of the immunizer conjugation, What's more Subsequently upgrading the affectability about antigen identification [33].

\section{References}

[1] J.P.Dubey Review of "Toxoplasmosis of animals and humans (second edition) " Parasit. Vectors, Vol.3, PP. 112,2010. 
[2] L. Pusch, B .Romeike, M.Deckert , C. Mawrin,Persistent Toxoplasma bradyzoite cysts in the brain Incidental finding in an immunocompetent patient without evidence of a toxoplasmosis. Clin. Neuropathol, Vol.28(3), PP. 210-212,2009.

[3] J.P. Dubey , J.L.Jones Toxoplasma gondii infection in humans and animals in the United States. Int. J. Parasitol, Vol.38, PP.125778,2008 .

[4] J.G. Montoya , J.S. Remington, Management of Toxoplasma gondii infection during pregnancy. Clin. Infect. Dis, Vol.47(4), PP. 554-66,2008.

[5] W.N.A. Van Der Puije, , K.M. Bosompem, E.A. Canacoo, J.M.Wastling, B.D.Akanmori, The prevalence of anti-Toxoplasma gondii antibodies in Ghanaian sheep and goats. Acta. Tropica, Vol.76, PP.21-26,2000.

[5] H.G. Fischer, S .Stachelhaus, M. Sahm, H.E.Meyer, G.Reichmann, GRA7, an excretory 29 Kda Toxoplasma gondii dense granule antigen released by infected host cells. Mol. Biochem. Parasitol, Vol.91, PP.251-62,1998.

[6] J .Hafid, , R .Tran Manh Sung, H. Raberin, Z.Y. Akono, B.Pozzetto , M.Jana, Detection of circulating antigens of Toxoplasma gondii in human infection. Am. J. Trop. Med. Hyg, Vol.52, PP. 336- 39,1995.

[7] L.H. Kasper, M.S. Bradley, E.R.Pfefferkorn ,Identification of stage specific sporozoite antigens of Toxoplasma gondii by monoclonal antibodies. J. Immunol, Vol.132, PP.443-9,1984.

[8] E .Handman, J.W. Goding, J.S .Remington,Detection and characterization of membrane antigens of Toxoplama gondii. J. Immunol, Vol.124(6), PP.2578-83,1980.

[9] N .Rachinel, D.Buzoni-Gatel, C.Dutta ,The induction of acute ileitis by a single microbial antigen of Toxoplasma gondii. J. Immunol; Vol.173, PP. 2725 - 35,2004.

[10] S.N. Aly , I. Bayoumi , R. Selem , M. Kardoush , G. Rashed, and Moharam A. A Novel Nano Magnetic Beads Dot ELISA Immunoassay and Its Application on the Detection of Giardia lamblia Coproantigen. Iran. J. Parasitol, Vol.13(4), PP.532-540,2018.

[11]R.G. Brooks, S.D. Sharma, J.S .Remington, Detection of Toxoplasma gondii antigen by a dot-immunobiding technique. J. Clin. Microbiol, Vol. 211, PP.13-6,1985.

[12] A .Timanova, S.Muä ller , T.Marti ,Ascaridia galli fatty acid binding protein, a member of the nematode polyprotein allergens family. Eur. J. Biochem, Vol.261, PP.569-76,1999.

[13]E.Engvall , P. Perlmanm, Enzyme-linked immunosorbent assay. Quantitative assay of IgG. Immunochem, Vol.887, PP.1-4,1971.

[14] B.O.Fagbemi, Development and characterization of a monoclonal antibody reactive with $128 \mathrm{kDa}$ protease of F. gigantica. Vet. Parasitol, Vol.573, PP.51-6,1995.

[15] A.Nowotny, A basic exercises in immunochemistry. In Nowotny A. editor. A Basic Exercises in Immunochemistry. 2nd ed. Berlin- Heidelberg-New York Springer-Verlag, Vol.5(3), PP.7-20,1979.

[16] M.M.Mckinney , A.Parkinson A simple, nonchromatographic procedure to purify immunoglobulins from ascites fluid. J. Immunol.Methods, Vol.962, PP.71-8.1987.

[17]E.Harlow , D.Lane , Antibodies A Laboratory Manual. 1st ed. New York Cold Spring Harbor Laboratory Press, Vol.854, PP.17-20,1988.

[18]E. Engvall , P Perlmann ,Enzyme-linked immunosorbentassay (ELISA).Quantitative assay of immunoglobulinG. Immunochemistry;Vol. 8(9), PP.871-4,1971.

[19]S.R. Ahmed , J. Kim , T .Suzuki , J Lee , E.Y. Park , Enhanced catalytic activity of gold nanoparticle-carbon nanotube hybrids for influenza virus detection. Biosens Bioelectron, Vol.85, PP.503 - 508,2016.

[20] K. Zhang , G. Lin , Y. Han , J .Li , Serological diagnosis of toxoplasmosis and standardization. Clin Chim Acta 1, Vol.461, PP. 83-9,2016.

[21] S .Jafar Pour Azami, H .Keshavarz, M. Rezaian, M. Mohebali , S.Shojaee, Rapid detection of Toxoplasma gondii antigen in experimentally infected mice by Dot- ELISA. Iran. J. Parasitol, Vol.563, PP. 628-33,2011.

[22]I .Aly , E.E. Taher , G. El Nain , H. El Sayed, F.A .Mohammed , R.S. Hamad , E.M. Bayoumy ,Advantages of bioconjugated silica-coated nanoparticles as an innovative diagnosis for human toxoplasmosis.Acta Trop, Vol.177, PP.19-24,2018.

[23]Z. Wang, J. Hu, Y. Jin, X.Yao , J.Li, In situ amplified chemiluminescent detection of DNA and immunoassay of IgG using special-shaped gold nanoparticles as label. Clin. Chem; Vol.52(10), pp.1958-1961,2006.

[24] S. Hegazy, A. Farid, I.Rabae , A.El-Amir, Novel IMB-ELISA assay for rapid diagnosis of human toxoplasmosis using SAG1 antigen. Jpn. J. Infect. Dis , Vol.68(6), PP.474-80 ,2015.

[25]H. Yang, Q.Guo , R.He, A quick and parallel analytical method based on quantum dots labeling for to $\mathrm{RCH}$-related antibodies. Nanoscale Res. Lett, Vol.4 , PP.1469 $-1474,2009$.

[26] B.S.S. Guirgis, e. Sa', C. Cunha, I. Gomes, M. Cavadas, I .Silva, G. Doria, G.L. Blatch, P.V. Baptista, E.Pereira, Gold nanoparticle-based fluorescence immunoassay for malaria antigen detection. Anal. Bioanal. Chem, Vol.402, PP. 1019-1027,2012. 
[27]R. Thiramanas, K .Jangpatarapongsa, U .Asawapirom, P.Tangboriboonrat , D.Polpanich, Sensitivity and specificity of PS/AA-modified nanoparticles used in malaria detection. Microb. Biotechnol; Vol.6, PP.406$413,2013$.

[28] A .Hemadi, A. Ekrami, H. Oormazdi, A.R. Meamar, L.Akhlaghi , A.R.Samarbaf-Zadeh, Bioconjugated fluorescent silica nanoparticles for the rapid detection of Entamoeba histolytica. Acta. Trop, Vol.145, PP.26-30,2015.

[29] S.M. Rashed, M.E. Nasr, I.A. Shalash, N.S. Ali, W.E. Elawamy, S.M. Kishik, A.El-Ghanam, Echinococcus granulosus protoscolex antigen used in serodiagnosis of hydatidosis by nano- gold dot-ELISA. PUJ, Vol.12(2) , PP. 110 115,2019 .

[30]M. Kamel, H. El-Baz, Z .Demerdah, S. ElKaraksy, N. El-Gendy, S.Hassan, Nanoimmunoassay for diagnosis of active schistosomal infection. World J Med Sci, Vol.13(1), PP.27-37,2016.

[31] Y. Hu , D.H. Fine, E. Tasciotti, A.Bouamrani , M.Ferrari ,Nanodevices in diagnostics. Wiley Interdiscip Rev Nanomed Nanobiotechnol, Vol.3(1), PP. 11-32,2011.

[32] L. Chen, H. Wei, Y .Guo, Z .Cui, Z.Zhang, X.E. Zhang,Gold nanoparticle enhanced immunoPCR for ultrasensitive detection of Hantaan virus nucleocapsid protein. J. Immunol. Methods, Vol.346 (1), pp.64 - 70,2009. 